\title{
Estudo da Interação de um Begomovírus Isolado de Tomateiro com a Mosca Branca
}

\author{
Carmem D. G. Santos', Antonio C. de Ávila² \& Renato de O. Resende ${ }^{3}$ \\ 'Departamento de Fitopatologia, Universidade de Brasília, CEP 70910-970, Brasília, DF, e-mail: carmelo@ ufc.br; ${ }^{2}$ EMBRAPA \\ Hortaliças, Cx. Postal 218, CEP 70359-970, Brasília-DF, e-mail: avila@ cnph.embrapa.br; ${ }^{3}$ Departamento de Biologia Celular, \\ Universidade de Brasília, CEP 70910-970, Brasília-DF, e-mail: rresende@unb.br
}

(Aceito para publicação em 04/11/2003)

Autor para correspondência: Carmem Dolores Gonzaga Santos

SANTOS, C.D.G., ÁVILA, A.C. \& RESENDE, R.O. Estudo da interação de um begomovírus isolado de tomateiro com a mosca branca. Fitopatologia Brasileira 28:664-673. 2003.

\section{RESUMO}

No estudo da interação de um begomovírus isolado de tomateiro (Lycopersicon esculentum) em Anápolis-GO, denominado GO-ANPL (taxonomicamente relacionado ao Tomato rugose mosaic virus, ToRMV) com o vetor Bemisia tabaci biótipo B, determinaramse o período de acesso de aquisição do vírus (PAA), o período de acesso de inoculação (PAI), o período de latência (PL), a sua retenção e transmissão à progênie. Nos experimentos empregaram-se plantas de tomateiro 'Santa Clara' e cinco insetos por planta. Constatou-se um PAA mínimo de 15 min com o qual $6 \%$ dos tomateiros foram infetados. Este percentual aumentou para $65 \%$ quando o PAA foi estendido para $24 \mathrm{~h}$. O PAI mínimo foi de $30 \mathrm{~min}$ registrando-se $18 \%$ de infecção, o qual foi elevado para $67 \%$ com $24 \mathrm{~h}$ de PAI. Observou-se o término do PL $16 \mathrm{~h}$ após o vetor adquirir o vírus. $\mathrm{Na}$ detecção do GO-ANPL no vetor via PCR, testes com mais de 2.500 espécimens constataram o vírus em ninfas desenvolvidas em tomateiro infetado, em adultos com diferentes PAAs, mas não em ovos de fêmeas avirulíferas ovipositados em planta infetada. Observou-se a passagem transestadial em $100 \%$ dos adultos testados que transmitiram o vírus em $33 \%$ dos casos. Evidenciou-se a transmissão à progênie pela detecção do vírus em ovos, ninfas e adultos provenientes de fêmeas virulíferas, contudo, a transmissão do vírus pelos adultos não foi observada. Os resultados obtidos indicam que a interação vírus-vetor é estabelecida desde a fase inicial do desenvolvimento do inseto e podem ser considerados relevantes para os estudos epidemiológicos dos begomovírus associados ao biótipo $\mathrm{B}$ de B. tabaci no país.

Palavras-chave adicionais: interação vírus-vetor, Geminiviridae, Lycopersicon esculentum, PCR.

\section{ABSTRACT}

Studies of the interaction of a new begomovirus isolate from tomato with the whitefly

A begomovirus named GO-ANPL (taxonomically related to the Tomato rugose mosaic virus, ToRMV), obtained from tomato (Lycopesricon esculentum) plants in Anápolis, state of Goiás, was used to study virus/vector (Bemisia tabaci biotype B) interaction. The acquisition access period (AAP), the inoculation access period (IAP), and the latent period (LP) were determined by transferring five whiteflies per tomato seedling cv. Santa Clara. The minimum AAP was 15 min resulting in $6 \%$ infected plants, which reached $65 \%$ as the length of AAP increased to $24 \mathrm{~h}$. At a minimum IAP of $30 \mathrm{~min}, 18 \%$ of plants were infected; this increased to $67 \%$ after an IAP of $24 \mathrm{~h}$. The end of the LP in the vector occurred $16 \mathrm{~h}$ after virus acquisition. To detect the GO-ANPL in the vector by PCR, more than 2,500 specimens were tested. The virus was found in adults under different AAPs from the $1^{\text {st }}$ to the $4^{\text {th }}$ instar grown on infected plants. No virus was found in the eggs that were laid on infected plants by aviruliferous females. The GO-ANPL isolate was transmitted to the progeny of viruliferous females, since the virus was detected in eggs, all instars and adults. However, no virus transmission was observed from these adults. A high frequency of viral detection was observed in newly emerged adults from immature forms reared on virus-infected plants. These adults infected $33 \%$ of tomato plants in virus transmission assays. The results indicate that the interaction between begomovirus and B. tabaci biótipo B starts at early stages of insect development. This is important information for epidemiological studies of begomovirus in this country.

\section{INTRODUÇÃO}

Os begomovírus, vírus da família Geminiviridae transmitidos por mosca branca, constituem sérios patógenos de culturas agronômicas e hortícolas em regiões tropicais e subtropicais em todo o mundo. A partir da década de 80, tornaram-

\footnotetext{
*Parte de Tese de doutorado do primeiro autor. Universidade de Brasília (2001)
}

se freqüentes os relatos da disseminação da mosca branca, Bemisia tabaci Gennadius biótipo B (B. argentifolii Bellows \& Perring), e de begomovírus provocando impacto devastador nas regiões em que ocorrem (Brown et al., 1995). No Brasil, os begomovírus foram relatados nas culturas do feijoeiro (Phaseolus vulgaris L.), tomateiro (Lycopersicon esculentum Mill.), feijão de corda (Vigna unguiculata Walp.), soja (Glycine max Merril) e pimentão (Capsicum annuum L.). No Distrito Federal, a 
Estudo da interação de um begomovírus isolado de tomateiro com...

presença de begomovírus em tomateiro foi relatada a partir de 1994, causando, no ano seguinte, perdas que variaram de $40 \%$ a 100\% (Bezerra et al., 1996). Esse relato sucedeu à constatação da mosca branca no Distrito Federal em 1993 (França et al., 1996). A partir de 1996, elevada incidência de begomovírus em tomateiro foi observada nos estados de Minas Gerais, Bahia, São Paulo, Pernambuco, Rio de Janeiro, Goiás e Ceará, sendo muitas vezes, relatado como limitante para a produção do tomate em várias áreas de cultivo (Faria et al., 2000).

Os begomovírus não são transmitidos por semente ou por contato entre plantas infetadas e sadias. Sua dispersão ou introdução no campo dá-se pela ação da mosca branca a partir de fontes de vírus de áreas próximas, podendo ser de cultivos antigos como também de fontes alternativas no campo (Costa, 1976). Diversidade genética tem sido observada em espécies de begomovírus associadas ao tomateiro no Nordeste, Sudeste e Centro-Oeste do Brasil (Ribeiro et al., 2003), e o relacionamento genético observado entre as espécies de tomate e de plantas daninhas sugerem que os vírus sejam provenientes de plantas nativas e que estão sendo transferidos para o tomateiro pela mosca branca, B. tabaci biótipo B (Ambrozevicius et al., 2002). Segundo Villas-Bôas et al. (1999) o biótipo B tem se dispersado nos campos rapidamente, sendo considerada a espécie de mosca branca que comumente devasta os cultivos agrícolas nas várias regiões geográficas do país.

A modalidade de transmissão de begomovírus por moscas brancas, Bemisia spp., é do tipo circulativa, não propagativa (Brown, 1997; Rubinstein \& Czosnek, 1997; Ghanim et al., 1998; Morin et al., 1999). A relação entre os begomovírus e a mosca branca, incluindo diversas características de transmissão do vírus pelo vetor, tais como período de aquisição, de inoculação, de latência, de retenção, passagem transovariana, entre outros, foram estudadas em alguns países, envolvendo begomovírus de cucurbitáceas, como Squash leaf curl virus (SLCV) (Cohen et al., 1989), de algodão (Gossypium hirsutum L.) como o Cotton leaf curl virus (CLCuV) (Nateshan et al., 1996) e de tomate, principalmente o Tomato yellow leaf curl virus (TYLCV) (Picó et al., 1996; Ghanim et al., 1998; Muniappa et al., 2000) espécies não relatadas no Brasil. Nesses estudos, os resultados obtidos foram variáveis e relacionados à estirpe viral envolvida, à região geográfica e às condições de cada pesquisa.

Considerando a importância dos begomovírus para a cultura do tomate, sua associação com a mosca branca e a relativa escassez de informações sobre o relacionamento desses vírus com o vetor, $B$. tabaci biótipo B, no Brasil, realizou-se este trabalho, o qual teve por objetivo investigar a interação de um begomovírus isolado de tomate com a mosca branca nas diferentes fases de seu desenvolvimento, e determinar as características de transmissão pelo adulto, visando, contribuir para os estudos epidemiológicos de begomovírus de tomate nas condições brasileiras.

\section{MATERIALEMÉTODOS}

\section{Origem do isolado de begomovírus e da população do vetor}

O isolado viral empregado no estudo da interação vírus- vetor foi obtido de tomate indústria 'Jumbo,' coletado em lavouras no município de Anápolis, Estado de Goiás, apresentando sintomas de mosaico, clorose internerval e enrolamento do limbo foliar. O vírus foi previamente identificado como pertencente ao gênero Begomovirus por meio de PCR com "primers" específicos (Santos et al., 1998) e mediante análise de sequiência nucleotídica do componente A (Santos et al., 2002b). Análises preliminares da sequência de nucleotídeos de grande parte do genoma do componente A, envolvendo a região intergênica, a capa protéica, e parte da replicase sugerem que o isolado, denominado GO-ANPL, seja uma variante ou uma espécie próxima ao Tomato rugose mosaic virus (ToRMV), espécie recentemente identificada em tomateiro no Brasil (Ribeiro et al., 2003).

A população inicial do vetor $B$. tabaci biótipo $\mathrm{B}$, foi cedida pela Dra. Geni Villas-Bôas (Embrapa Hortaliças). As colônias do inseto foram mantidas em plantas envasadas de repolho (Brassica oleracea L. var. capitata) e couve (Brassica oleracea L. var. acephala), espécies não hospedeiras do begomovírus, em insetários protegidos com malha de náilon à prova de insetos.

\section{Condução dos ensaios de transmissão do isolado GO-ANPL pelo vetor}

Os ensaios de detecção e de transmissão do isolado GO-ANPL pelo vetor foram conduzidos na Embrapa HortaliçasDF, com temperatura variando de 14 a $20^{\circ} \mathrm{C}$, de maio a julho, e de 20 a $24^{\circ} \mathrm{C}$, de julho a setembro de 2000 .

Para a realização dos ensaios de transmissão pelo vetor, empregaram-se adultos com no máximo três dias da emergência, coletados de plantas de couve e repolho com o auxílio de um aspirador adaptado para insetos. A passagem das moscas brancas das brássicas para tomate sadio precederam os tratamentos, para efeito da adaptação do vetor à solanácea. Para a inoculação, foram usadas mudas sadias de tomate 'Santa Clara' no estágio de duas folhas verdadeiras cultivadas em copos descartáveis de café contendo uma mistura de solo e esterco esterilizados. Os procedimentos adotados, e descritos a seguir, foram similares na determinação do período de acesso de aquisição do vírus (PAA), do período de acesso de inoculação (PAI) e do período de latência (PL).

\section{Aquisição do vírus pelo vetor}

Folhas novas ( $1^{\mathrm{a}}$ a $3^{\mathrm{a}}$, do ápice para a base) de 'Santa Clara' com três a quatro semanas da inoculação, foram destacadas e dispostas em tubos "falcon". Grupos de pelo menos 100 moscas brancas avirulíferas foram transferidas para cada tubo, previamente identificados para cada PAA. Este procedimento foi adotado nos ensaios para determinação do PAA e do PL, nos quais o tempo máximo de permanência de folhas e insetos nos tubos foi de $24 \mathrm{~h}$. Nos ensaios visando a determinação do PAI, em virtude da necessidade de um maior número de insetos com PAA mais longo (72 h), dispuseram-se as folhas destacadas com pecíolos imersos em vidros com água, para conservar a sua turgidez. Os vidros com as folhas foram então dispostos em recipientes plásticos e cobertos com 
tecido escaline, para evitar a fuga dos insetos ali introduzidos.

\section{Transmissão do vírus pelo vetor}

Decorrido o PAA de cada ensaio, conduziram-se os tubos "falcon" ou recipientes plásticos com folhas e insetos para serem abertos em caixa de papelão revestida com duplex preto. As folhas foram retiradas dos tubos e, com leves movimentos das folhas, provocou-se a saída do vetor para o teto da caixa. As moscas brancas foram coletadas da caixa escura, com o auxílio de ponteiras plásticas com pontas vedadas do pipetador automático P-20 e transferidas, em grupos de cinco, para plântulas individuais de tomate. As plantas foram imediatamente cobertas com gaiolas confeccionadas com copos descartáveis de $300 \mathrm{ml}$, cujo fundo foi substituído por tecido escaline, para conter os insetos. Ao final do período da inoculação, as moscas brancas foram eliminadas, as plantas pulverizadas com inseticida sistêmico e transferidas em bandejas plásticas para casa de vegetação.

\section{Determinação do período de acesso de aquisição do vírus, PAA}

Avaliaram-se nove períodos de acesso de aquisição do vírus pelo vetor: $15 \mathrm{~min}, 30 \mathrm{~min}, 1 \mathrm{~h}, 2 \mathrm{~h}, 4 \mathrm{~h}, 8 \mathrm{~h}, 16 \mathrm{~h}, 20 \mathrm{~h}$ e 24 $\mathrm{h}$, visando-se identificar o período mínimo para a aquisição e os percentuais de transmissão do vírus em cada caso. Para tanto, após cada PAA, as moscas brancas foram transferidas para plantas sadias (cinco insetos por planta), onde permaneceram por $48 \mathrm{~h}$. O experimento foi conduzido com cinco repetições de grupos de dez plantas submetidas a cada um dos nove tratamentos, num total de 450 plantas inoculadas. Após 15 dias em condições de casa de vegetação, as amostras das brotações de cada planta, com ou sem sintomas, foram coletadas e testadas individualmente por hibridização. $\mathrm{O}$ percentual médio de plantas infetadas foi definido e analisado estatisticamente empregando-se a regressão não-linear e o modelo logarítmico que melhor se adequou para a avaliação dos dados.

\section{Determinação do período de acesso de inoculação do vírus, PAI}

Foram definidos nove períodos de acesso de inoculação do vírus pelo vetor: $15 \mathrm{~min}, 30 \mathrm{~min}, 1 \mathrm{~h}, 2 \mathrm{~h}, 4 \mathrm{~h}, 8 \mathrm{~h}, 16 \mathrm{~h}, 20 \mathrm{~h}$ e $24 \mathrm{~h}$, visando-se determinar o período mínimo para a inoculação e os percentuais de transmissão para cada período. Foi adotado um único PAA de 72 h pelo vetor e após cada PAI nas plantas de tomate, as moscas brancas foram eliminadas. A confirmação de infecção nas plantas e a análise estatística foram conduzidas conforme o procedimento anterior.

\section{Determinação do período de latência do vírus no vetor, $\mathrm{PL}$}

Empregaram-se cinco períodos de acesso de aquisição do vírus em folhas destacadas: 8 h, 12 h, 16 h, 20 h e 24 h. Após o PAA, os insetos foram transferidos para tomate onde permaneceram, continuamente, por $4 \mathrm{~h}, 8 \mathrm{~h}, 12 \mathrm{~h}, 16 \mathrm{~h}$ ou $20 \mathrm{~h}$ (PAI). Na avaliação desta variável, considerou-se o tempo total do vírus na mosca branca, dado pela soma do PAA e PAI, para se verificar o início da transmissão do vírus, ou seja, o término do período de latência no vetor. O número de plantas inoculadas por combinação (PAA+PAI) variou de 20 a 30 e, decorrido o período de observação, foi calculado o percentual de plantas infectadas pelo vírus.

\section{Detecção do GO-ANPL nas amostras foliares}

Para a detecção do begomovírus nas amostras foliares dos ensaios de PAA, PAI e PL, foi empregada a técnica "dotblot" (Rom et al., 1993). Extratos de amostras foliares, trituradas na presença de $\mathrm{NaOH} 0,4 \mathrm{~N}$, foram gotejados em membranas de náilon (Hybond $\mathrm{N}+$ da Amersham/Pharmacia) que, após lavagens em Tris- $\mathrm{HCl}$ pH 7,5, em 2 X SSC ( $\mathrm{NaCl} 3 \mathrm{M}$, citrato de sódio 0,3 M), imersão em etanol 95\% e fixação do DNA sob UV, foram hibridizadas em sondas preparadas com fragmento do DNA A do GO-ANPL marcado com o $\alpha-{ }^{32} \mathrm{P}$ e avaliadas por autoradiografia.

\section{Detecção do GO-ANPL no vetor coletado de planta infetada}

A presença do vírus foi investigada nas diversas fases de desenvolvimento da mosca branca: em ovos de fêmeas avirulíferas, cinco a sete dias após serem ovipositados em tomateiro infetado, nos quatro ínstares do vetor que se desenvolveram em planta infetada e em adultos com PAA de $15 \mathrm{~min}$ a $24 \mathrm{~h}$. A passagem transestadial do vírus no vetor foi investigada a partir de adultos emergidos de ninfas cujo $4^{\circ}$ ínstar foi transferido da planta infetada para folhas de couve, espécie não suscetível ao vírus. Em ensaios que visaram avaliar a retenção do vírus de ninfas do $1^{\circ}$ ínstar para os estágios posteriores, transferiram-se exemplares dessas ninfas de plantas infetadas para planta couve e aguardando-se o seu desenvolvimento.

\section{Detecção do GO-ANPL na progênie do vetor}

Nos testes para detecção de transmissão do vírus à progênie transferiram-se fêmeas, individualmente, de tomateiro infetado para couve ou repolho, confinando-as às plantas por $24 \mathrm{~h}$ a $48 \mathrm{~h}$. Após esse período, as fêmeas foram testadas quanto à presença de vírus, e somente as progênies de fêmeas confirmadamente virulíferas foram coletadas. Obtiveram-se amostras de ovos e, à medida que iam se desenvolvendo, amostras de ninfas de $1^{\circ}$ ao $4^{\circ}$ ínstar e de adultos emergentes.

As transferências de ninfas e as coletas de ovos, ninfas e adultos foram realizadas com o auxílio de pincel fino e microscópio estereoscópico. Em virtude do elevado número de amostras, os exemplares coletados e transferidos para microtubos contendo tampão de extração (Tris-EDTA 0,1 M $\mathrm{pH} 9,0,1 \%$ SDS ) foram acondicionados $\mathrm{a}-20^{\circ} \mathrm{C}$ para posterior extração de DNA.

\section{Extração do DNA a partir da mosca branca}

O DNA foi extraído de ovos em grupos de até 20 exemplares, de cada um dos quatro ínstares em grupos de até dez, e de adultos em conjunto de até seis. A coleta individual ocorreu para fêmeas usadas nos ensaios de progênie e adultos na investigação da passagem transestadial. A extração do DNA baseou-se na metodologia empregada por Metha et al. (1994a). 
Estudo da interação de um begomovírus isolado de tomateiro com...

Insetos congelados em TE foram triturados nos microtubos com auxílio de pistilos plásticos, com adição de 1 $\mu 1$ de proteinase $\mathrm{K}(50 \mu \mathrm{g} / \mathrm{ml})$, incubação a $65^{\circ} \mathrm{C}$, adição de 3,5 $\mu \mathrm{l}$ de acetato de potássio $8 \mathrm{M}$, tratamento com clorofórmio/ fenol, precipitação do DNA com etanol e ressuspensão em água milli-Q. As amostras de DNA total foram mantidas a -20 ${ }^{\circ} \mathrm{C}$ para posterior uso na PCR.

A extração de DNA a partir de folhas de tomateiro, a ser empregado como testemunha, foi realizada conforme o método desenvolvido por Dellaporta et al. (1983).

\section{Realização da PCR das amostras}

Para a PCR, empregaram-se 5,0 $\mu 1$ de DNA total do inseto (ovos, ninfas ou adultos) ou $2 \mu \mathrm{l}$ de DNA de tomateiro, 2,5 $\mu \mathrm{l}$ tampão 10X da enzima Taq DNA polimerase (Pharmacia), $1 \mu \mathrm{lde}$ dNTP (Pharmacia) a 2,5 mM, 10 pmoles $(0,7 \mu \mathrm{l})$ de cada oligonucleotídeo iniciador, $1 \mathrm{U}(0,2 \mu \mathrm{l})$ de Taq DNA polimerase (Pharmacia), ajustando o volume da reação para $25 \mu \mathrm{lcom}$ água (filtro Milli-Q) estéril. Constituíram o controle positivo, o DNA extraído de adultos com PAA de 48 h, DNA de planta infetada com o GO-ANPL e DNA plasmidial do Bean golden mosaic virus (BGMV). O controle negativo incluiu DNA de ovos, ninfas e adultos de colônias avirulíferas e DNA de tomateiro sadio. Utilizou-se o par de oligonucleotídeos 5'-CCCGTCGACATGYCTAAGMGKGAKGCCCC-3' (CP1) e 5'-CCCCTGCAGAACTTCCAAGTCTGGACG-3' (CP2), que amplificam fragmentos de $0,9 \mathrm{~kb}$ do DNA A, referente a capa protéica do vírus. Foi utilizado o termociclador modelo PTC $100 \mathrm{MJ}$ Research, adotando-se um programa com aquecimento inicial de $94^{\circ} \mathrm{C}$ por 3 min e 33 ciclos compostos de: desnaturação $\left(94^{\circ} \mathrm{C} / 1 \mathrm{~min}\right)$, anelamento $\left(52^{\circ} \mathrm{C} / 1 \mathrm{~min}\right)$, extensão $\left(72^{\circ} \mathrm{C} / 1 \mathrm{~min}\right)$ e extensão final a $72{ }^{\circ} \mathrm{C}$ por $7 \mathrm{~min}$. Após a eletroforese, os fragmentos de DNA amplificados foram visualizados em gel de agarose corado com brometo de etídio e observado sob luz UV. Ocasionalmente, "southern blot" (Metha et al., 1994a) das amostras foi também realizado.

\section{Transmissibilidade do vírus por adultos oriundos da progênie e da passagem transestadial}

Para avaliar a transmissibilidade do vírus para tomateiros sadios, adultos da progênie de fêmeas virulíferas e adultos oriundos da passagem transestadial, e que não tiveram acesso à fonte de vírus, foram transferidos em grupos de dez a 15 para mudas de tomate, nas quais permaneceram por $48 \mathrm{~h}$. Após esta etapa, os adultos foram coletados, individualmente, para detecção do vírus por PCR, conforme procedimento anteriormente descrito, permanecendo as plantas inoculadas sob observação em casa de vegetação.

\section{RESULTADOS}

Nos experimentos para definição de PAA, PAI e PL, as plantas de tomate infetadas com o GO-ANPL apresentaram sintomas iniciais de mosqueado e clareamento de nervuras aos oito dias após a inoculação, e ao décimo quinto dia, sintomas de mosaico internerval e deformação foliar estavam bem definidos, independente do tempo de inoculação concedido.

\section{Período de acesso de aquisição do vírus, PAA}

Os resultados dos experimentos realizados para a determinação do PAA, confirmados com o "dot blot" (Figura 1A, Tabela 1). A análise estatística da média dos dados usando o modelo de regressão não linear está ilustrada na Figura 1B. Nos ensaios constatou-se que $B$. tabaci biótipo B, foi capaz de adquirir o begomovírus a partir de um PAA de apenas 15 min com o qual transmitiu o vírus para o tomateiro em um percentual médio de $6 \%$. Este percentual aumentou à medida que o PAA dos insetos foi estendido alcançando os $65 \%$ quando esse período foi de $24 \mathrm{~h}$ (Tabela 1). O modelo logarítmico foi o que melhor se adequou à análise dos dados.

\section{Período de acesso de inoculação do vírus, PAI}

Os resultados dos experimentos realizados para a determinação do PAI (Tabela 2) foram confirmados com o "dot blot" (Figura 1C). Segundo a análise estatística da médias dos dados usando o modelo de regressão não-linear (Figura 1D). Observou-se que a mosca branca virulífera (PAA 72 h), nas condições desses experimentos, foi capaz de transmitir o vírus aos 30 min de PAI para 19\% das plantas de tomate. O percentual médio de transmissão aumentou com a extensão do PAI, havendo infecção em 66,7\% das plantas submetidas a 24 h de PAI.

\section{Período de latência no vetor, $\mathrm{PL}$}

De acordo com os resultados dos experimentos para determinação do período de latência (Tabela 3), observou-se que o início da transmissão do vírus para tomateiro, término do PL, ocorreu a partir da combinação que somou $16 \mathrm{~h}$ no vetor $(8 \mathrm{~h}+8 \mathrm{~h})$, quando $3,4 \%$ das plantas de tomate foram infetadas. Percentual pouco acima deste $(4,0 \%)$ foi obtido quando o tempo no vetor foi de $20 \mathrm{~h}(8 \mathrm{~h}+12 \mathrm{~h}$ ou $16 \mathrm{~h}+4 \mathrm{~h})$. Nas combinações que resultaram nos tempos de $24 \mathrm{~h}, 28 \mathrm{~h}$ e $32 \mathrm{~h}$, o percentual médio de plantas infetadas foi de $6,5 \%, 11,9 \%, 12,7 \%$, respectivamente. Um total de $25 \%$ de infecção foi observado para os casos em que o inseto permaneceu na planta até que se completassem $40 \mathrm{~h}$ do vírus no vetor, tanto para a combinação $16 \mathrm{~h}+24 \mathrm{~h}$ como $24 \mathrm{~h}+16 \mathrm{~h}$.

\section{Detecção do begomovírus no vetor}

Os resultados dos testes de detecção do begomovírus no vetor (Figura 2, Tabela 4) foram confirmados por "southern blot". O vírus foi detectado nos quatro estágios ninfais que se desenvolveram em planta infetada com valores crescentes de 15,4 a $70 \%$, do $1^{\circ}$ ao $4^{\circ}$ ínstar. Dessa última fase do inseto, o fragmento do DNA viral amplificado foi sempre mais facilmente observado no gel (Figura 2). O GO-ANPL não foi detectado em nenhuma das 27 amostras de ovos testadas, provenientes de fêmeas avirulíferas, cinco a sete dias após a oviposição em tomate infetado. Estas amostras envolveram mais de 500 ovos coletados de diferentes plantas de tomate infetadas. A passagem transestadial do vírus, por outro lado, foi detectada 
A

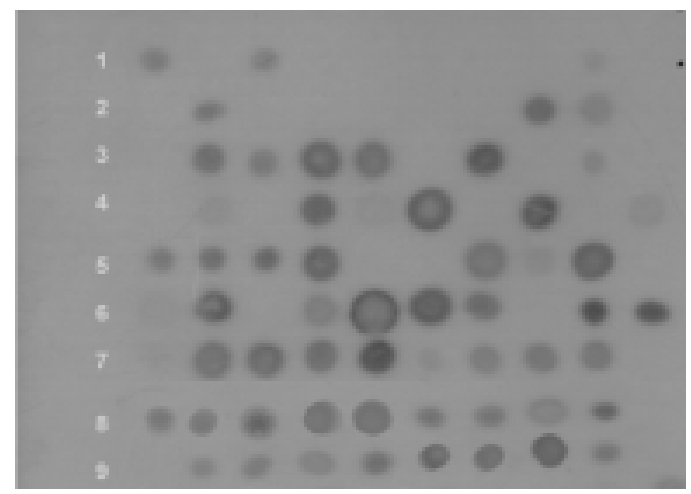

C

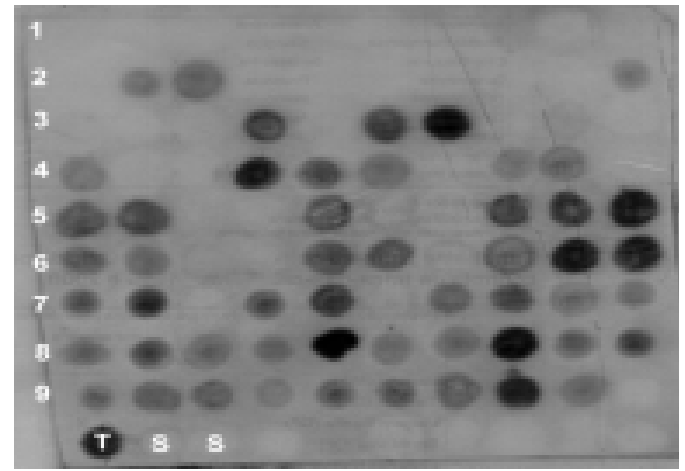

B

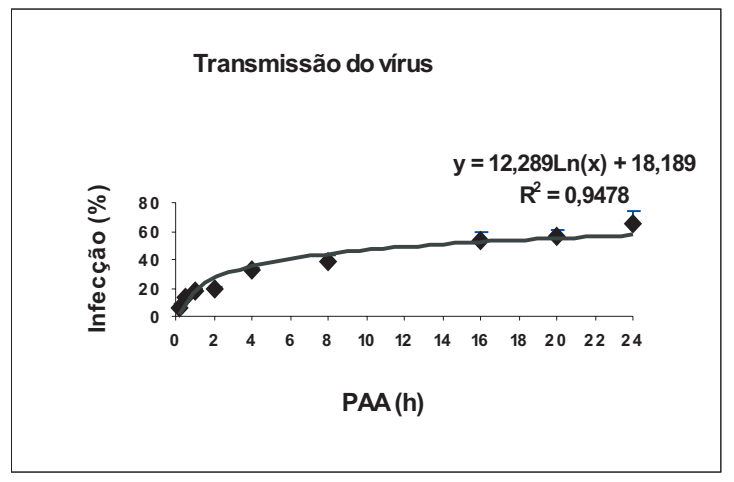

D

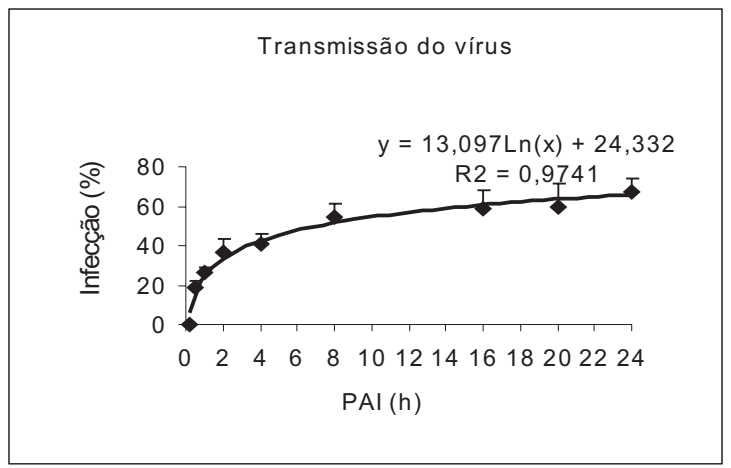

FIG. 1 - Análise da transmissão do begomovirus GO-ANPL pela mosca branca (Bemisia tabaci biótipo B): (A)"dot-blot" de amostras foliares de tomate (Lycopersicon esculentum) 'Santa Clara' após diferentes períodos de acesso de aquisição do vírus (PAA) e período de acesso de inoculação (PAI) fixo de 48 h. Linhas de 1 a 9 - amostras de plantas com PAA de 15 min a 24 h; (B) curva representando o percentual de transmissão com os períodos crescentes de PAA; (C) "dot blot" de amostras foliares coletadas após PAA fixo de 72 h e PAI variável. Linhas de 1 a 9 - amostras de plantas com PAI de $15 \mathrm{~min}$ a $24 \mathrm{~h} ; \mathrm{S}=$ extrato de planta sadia, $\mathrm{T}=$ extrato de tomate infetado; (D) curva representando o percentual de transmissão com os períodos crescentes de PAI.

em todas as amostras individuais testadas, sugerindo que a passagem do vírus da fase de ninfa para o adulto ocorre com elevada freqüência em condições naturais. Não foi possível avaliar a retenção do vírus da fase de $1^{\circ}$ ínstar para os estágios

TABELA 1 - Percentual de transmissão do isolado do begomovirus GO-ANPL pela Bemisia tabaci biótipo B para tomateiro (Lycopersicon esculentum) Santa Clara', após diferentes períodos de acesso de aquisição do vírus pelo vetor (PAA) e um período de acesso de inoculação (PAI) fixo de 48 h. Brasília-DF, 2001

\begin{tabular}{cc}
\hline \hline $\begin{array}{c}\text { Período acesso de } \\
\text { aquisição (horas) }\end{array}$ & $\begin{array}{c}\text { Total de plantas infetadas / } \\
\text { Plantas inoculadas }\end{array}$ \\
\hline 0,25 & $3 / 50(6,0)^{\mathrm{B}}$ \\
0,5 & $6 / 50(12,0)$ \\
1 & $9 / 51(17,6)$ \\
2 & $10 / 50(20,0)$ \\
4 & $17 / 51(33,3)$ \\
8 & $19 / 50(38,0)$ \\
16 & $26 / 49(53,0)$ \\
20 & $28 / 50(56,0)$ \\
24 & $32 / 49(65,0)$ \\
\hline A = Para a transmissão foram empregadas cinco moscas brancas / planta \\
de tomate; \\
B = Percentual de plantas infetadas em cada PAA.
\end{tabular}

posteriores, em virtude do insucesso da sobrevivência das ninfas transferidas (sete em 30 tentativas) para plantas sadias, ainda que sob cuidadosa manipulação. Nos exemplares testados quanto à retenção do vírus (cinco nas fases de $2^{\circ}$ a $4^{\circ}$

TABELA 2 - Percentual de transmissão do isolado do begomovirus GO-ANPL por Bemisia tabaci biótipo B para tomateiro (Lycopersicon esculentum) 'Santa Clara', após um período de acesso de aquisição fixo de $72 \mathrm{~h}$ e diferentes períodos de acesso de inoculação (PAI). Brasília-DF, 2001

\begin{tabular}{cc}
\hline \hline $\begin{array}{c}\text { Período acesso de } \\
\text { inoculação (horas) }\end{array}$ & $\begin{array}{c}\text { Total de plantas infetadas / } \\
\text { Plantas inoculadas }\end{array}$ \\
\hline 0,25 & $0 / 50(0,0)^{\mathrm{B}}$ \\
0,5 & $10 / 51(19,0)$ \\
1 & $13 / 48(27,0)$ \\
2 & $18 / 49(36,7)$ \\
4 & $20 / 49(40,8)$ \\
8 & $28 / 51(54,9)$ \\
16 & $29 / 49(59,1)$ \\
20 & $29 / 48(60,4)$ \\
24 & $34 / 51(66,7)$ \\
\hline A= Para a transmissão foram empregadas cinco moscas brancas / planta \\
de tomate; \\
B = Percentual de plantas infetadas com cada PAI.
\end{tabular}


Estudo da interação de um begomovírus isolado de tomateiro com...

TABELA 3 - Percentual de transmissão do begomovirus GO-ANPL por Bemisia tabaci biótipo B, na detecção do período de latência do vírus no vetor. Brasília-DF, 2001

\begin{tabular}{cc}
\hline \hline $\begin{array}{c}\text { Período total do vírus } \\
\text { no vetor (horas) }\end{array}$ & $\begin{array}{c}\text { Total de plantas infetadas / } \\
\text { plantas inoculadas }^{\mathbf{B}}\end{array}$ \\
\hline 12 & $0 / 36(0,0)^{\mathrm{C}}$ \\
16 & $1 / 29(3,4)$ \\
20 & $2 / 50(4,0)$ \\
24 & $4 / 61(6,5)$ \\
28 & $5 / 42(11,9)$ \\
32 & $22 / 173(12,7)$ \\
40 & $22 / 88(25,0)$ \\
\hline
\end{tabular}

$\mathbf{A}=$ Tempo do vírus no vetor resultante das diferentes combinações do período de acesso de aquisição + período de acesso de inoculação $(\mathbf{1 2} \mathbf{~ h}=$ $8 \mathrm{~h}+4 \mathrm{~h} ; \mathbf{1 6} \mathbf{h}=8 \mathrm{~h}+8 \mathrm{~h} ; \mathbf{2 0} \mathbf{h}=8 \mathrm{~h}+12 \mathrm{~h}$ e $16 \mathrm{~h}+4 \mathrm{~h} ; \mathbf{2 4} \mathbf{h}=8 \mathrm{~h}+16 \mathrm{~h}$; $16 \mathrm{~h}+8 \mathrm{~h}$ e $20 \mathrm{~h}+4 \mathrm{~h} ; \mathbf{2 8} \mathbf{h}=20 \mathrm{~h}+8 \mathrm{~h}$ e $24 \mathrm{~h}+4 \mathrm{~h} ; \mathbf{3 2} \mathbf{h}=12 \mathrm{~h}+20 \mathrm{~h}, 16$ $\mathrm{h}+16 \mathrm{~h} ; 20 \mathrm{~h}+12 \mathrm{~h}$ e $24 \mathrm{~h}+8 \mathrm{~h} ; 40 \mathrm{~h}=16 \mathrm{~h}+24 \mathrm{~h}$ e $24 \mathrm{~h}+16 \mathrm{~h} ; \mathbf{B}=$ total de plantas infetadas sobre o total de plantas inoculadas para as combinações que somaram o mesmo tempo no vetor; $\mathbf{C}=$ percentual e plantas infetadas em cada combinação.

ínstar e dois na fase adulta) o resultado foi negativo.

$\mathrm{O}$ vírus foi constatado nos adultos com PAA de $30 \mathrm{~min}$ a 24 h, mas não em adultos com o PAA de 15 min (Tabela 4), sendo maior o percentual de detecção nos casos em que o PAA foi mais prolongado.

A transmissão do begomovírus à progênie da mosca branca foi constatada em todas as fases do vetor, ou seja em ovos, ninfas e adultos provenientes de fêmeas virulíferas ovipositados em planta não hospedeira do vírus. Em ovos, o percentual foi de $13,8 \%$, sendo menor em ninfas de $1^{\circ}$ ao $3^{\circ}$ ínstar (4,3 a 8,3\%). No $4^{\circ}$ ínstar, o vírus foi constatado em $23,5 \%$ das amostras e na fase adulta em 16,0\% dos casos testados. Ocasionalmente, foram realizadas PCRs com o DNA de amostras foliares de couve obtidas do local onde se alimentavam as fases ninfais provenientes de fêmeas virulíferas. $\mathrm{O}$ resultado do teste, para todas as amostras vegetais empregadas, foi negativo.

\section{Transmissibilidade do vírus}

Nos testes de transmissibilidade do vírus pelos adultos da progênie de fêmeas virulíferas, não foi verificado nenhum caso de infecção dentre as 23 plantas de 'Santa Clara' submetidas a esses insetos. Por outro lado, nos casos em que os adultos foram emergentes de ninfas do $4^{\circ}$ ínstar coletadas de tomateiro infetado, e para os quais se confirmou, posteriormente, a passagem transestadial do begomovírus, as inoculações resultaram num percentual de $33 \%$ de transmissão viral após 48 h de PAI.

\section{DISCUSSÃO}

O isolado do Begomovirus GO-ANPL empregado neste trabalho, por ocasião de sua caracterização molecular, foi parcialmente seqüenciado e submetido à análises filogenéticas com begomovírus identificados no Brasil e em outros países. Os estudos comparativos realizados com a sequiência de
TABELA 4 - Percentual de detecção do begomovirus GO-ANPL em diferentes estádios de desenvolvimento de Bemisia tabaci biótipo B em planta infetada, em planta não hospedeira e em adultos com variados períodos de acesso de aquisição do vírus. Brasília-DF, 2001

\begin{tabular}{|c|c|}
\hline $\begin{array}{c}\text { Fase de desenvolvimento } \\
\text { do vetor }\end{array}$ & $\begin{array}{c}\text { Total de amostras positivas / } \\
\text { Amostras Testadas } \mathrm{G}\end{array}$ \\
\hline $\mathrm{Ovo}^{\mathrm{A}}$ & $0 / 27(0,0)^{\mathrm{H}}$ \\
\hline $1^{\circ}$ Ínstar & $2 / 13(15,4)$ \\
\hline $2^{\circ}$ Ínstar & $8 / 14 \quad(57,1)$ \\
\hline $3^{\circ}$ Ínstar & $7 / 10 \quad(70,0)$ \\
\hline $4^{\circ}$ Ínstar & $11 / 16 \quad(68,8)$ \\
\hline Adulto (transestadial) ${ }^{\mathrm{B}}$ & $8 / 8(100,0)$ \\
\hline $\mathrm{Ovo}^{\mathrm{C}}$ & $4 / 29(13,8)$ \\
\hline $1^{\circ}$ Ínstar & $1 / 12(8,3)$ \\
\hline $2^{\circ}$ Ínstar & $1 / 17(5,9)$ \\
\hline $3^{\circ}$ Ínstar & $1 / 23(4,3)$ \\
\hline $4^{\circ}$ Ínstar & $4 / 17(23,5)$ \\
\hline Adulto (emergente) & $4 / 25(16,0)$ \\
\hline $15 \min ^{D}$ & $0 / 3(0,0)$ \\
\hline $30 \mathrm{~min}$ & $3 / 8(37,5)$ \\
\hline $1 \mathrm{~h}$ & $2 / 6(33,3)$ \\
\hline $2 \mathrm{~h}$ & $4 / 6(66,7)$ \\
\hline $4 \mathrm{~h}$ & $5 / 8(62,5)$ \\
\hline $8 \mathrm{~h}$ & $4 / 7 \quad(57,1)$ \\
\hline $16 \mathrm{~h}$ & $5 / 7(71,4)$ \\
\hline $20 \mathrm{~h}$ & $3 / 4(75,0)$ \\
\hline $24 \mathrm{~h}$ & $6 / 6(100,0)$ \\
\hline Fêmea virulífera ${ }^{\mathrm{E}}$ & $26 / 42(61,9)$ \\
\hline Ovo $^{\mathrm{F}}$ & $0 / 12(0,0)$ \\
\hline $1^{\circ}$ ao $4^{\circ}$ Ínstar & $0 / 15(0,0)$ \\
\hline Adulto & $0 / 13(0.0)$ \\
\hline
\end{tabular}

$\mathbf{A}=$ ovo a $4^{\circ}$ ínstar - provenientes de fêmeas avirulíferas e desenvolvidos em tomate infetado; $\mathbf{B}=$ ninfa de $4^{\circ}$ ínstar transferida de tomate infetado para couve para emergência do adulto; $\mathbf{C}=$ ovo a adulto provenientes de fêmeas virulíferas e desenvolvidos em couve; $\mathbf{D}=$ adultos com PAA de 15 min a 24 h; $\mathbf{E}=$ fêmeas com PAA de 24 h e testadas individualmente; $\mathbf{F}=$ ovo a adulto provenientes de insetos avirulíferos; $\mathbf{G}=$ detecção por PCR: ovos, até 20 por tubo; ninfas até dez por tubo; adultos, até seis por tubo., $\mathbf{H}=$ Percentual de plantas infetadas.

nucleotídeos obtida de grande parte do genoma do componente A do GO-ANPL (Santos et al., 2002b), sugerem que esse isolado seja uma variante ou uma possível espécie próxima ao ToRMV, begomovírus recentemente relatado entre as novas espécies ocorrentes em tomateiro no Brasil (Ribeiro et al. (2003).

Em ensaios preliminares para a determinação do PAA, PAI e PL, a adoção de três insetos por planta causou mais escapes do que quando se usaram cinco insetos, e com este número os resultados foram similares ao uso de dez insetos. Para alguns vírus, como o Tomato leaf curl virus (TLCV) isolado de Bangalore, ToLCV-Ban4, a transmissão com um único adulto alcançou 40 a $65 \%$, no entanto, cinco insetos foram requeridos para os $100 \%$ de infecção (Muniyappa et al., 2000). Para o TYLCV, o emprego de cinco insetos resultou em uma transmissão máxima de $81 \%$, enquanto que $97 \%$ foram alcançados com a adoção de 20 insetos por planta (Metha et al., 1994b).

Na transmissão do GO-ANPL, fêmeas foram mais 

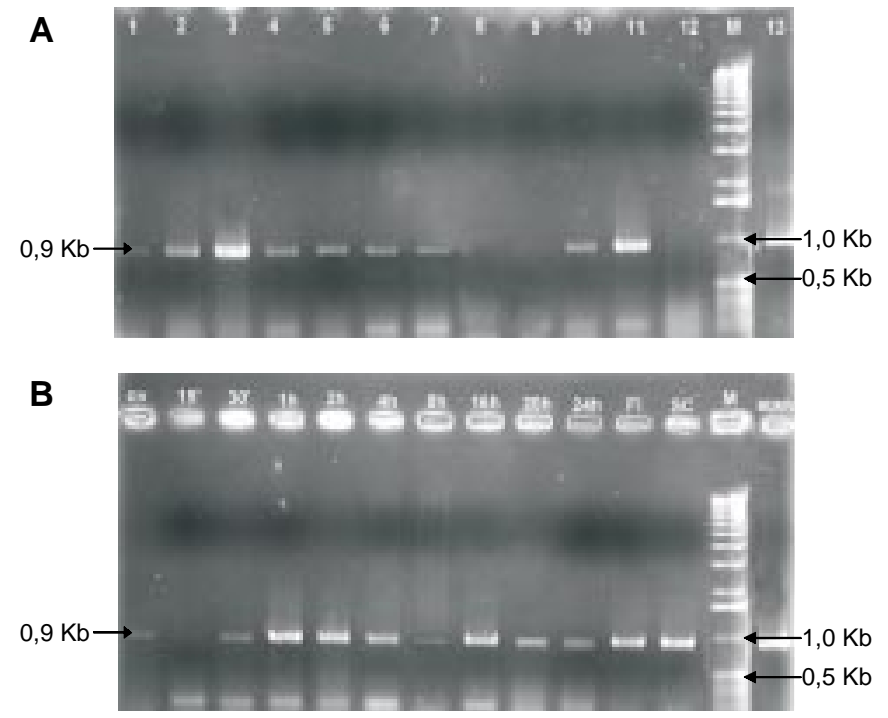

FIG. 2 - Análise eletroforética de amostras de mosca branca (Bemisia tabaci biótipo B) submetidas a PCR. A - Colunas 1 a 4 - ninfas de $1^{\circ}$, $2,,^{\circ} 4^{\circ}$ e $3^{\circ}$ ínstar coletadas em planta infetada; 5 a $7-1^{\circ}, 2^{\circ}$ e $4^{\circ}$ ínstar da progênie de fêmeas virulíferas; 8 - $4^{\circ}$ ínstar do ensaio de retenção de vírus; 9- adulto do ensaio de retenção de vírus; 10 - adultos da progênie de fêmea virulífera; 11- adultos da passagem transestadial; 12 - adulto avirulífero; $M=$ marcador DNA Ladder; 13- 'Santa Clara' infetada (controle). B - ovos de progênie de fêmea virulífera; $15 \mathrm{~min}$ a $24 \mathrm{~h}$ - adultos com período de acesso de aquisição do GO-ANPL de $15 \mathrm{~min}$ a $24 \mathrm{~h} ; \mathrm{Fi}=$ fêmea virulífera (individual); $\mathrm{SC}=$ tomate 'Santa Clara' infetado, $\mathrm{M}=$ marcador $1 \mathrm{~Kb}$ DNA Ladder; BGMVcontrole positivo.

freqüentemente empregadas que machos, em virtude de seu maior tamanho e de serem mais numerosas nas colônias. As fêmeas de mosca branca, em geral, são consideradas mais eficientes na transmissão de begomovírus que os machos (Nateshan et al., 1996; Muniyappa et al., 2000), porém, experimentos para comparar a eficiência entre machos e fêmeas na transmissão do GO-ANPL não foram conduzidos.

Nos ensaios de transmissão, verificou-se que ocorreu um percentual crescente da infecção viral em plantas de tomate com a extensão do PAA ou do PAI. Conforme observou-se na análise estatística, existe uma associação positiva entre as duas variáveis (percentual de infecção e PAA) expresso pela equação $\mathrm{Y}=12,289 \operatorname{Ln}(\mathrm{x})+18,189$. O elevado coeficiente de determinação $\left(\mathrm{r}^{2}\right)$ obtido para a curva $(0,9478)$, o qual mede a excelência do ajustamento da equação encontrada, sugere que os percentuais de infecção são explicados pela variação do PAA. Comportamento similar foi observado entre as variáveis do percentual de infecção e o PAI, cuja relação expressa pela equação $\mathrm{Y}=13,097 \operatorname{Ln}(\mathrm{x})+24,332$, obteve o coeficiente de determinação $\left(r^{2}\right)$ de 0,9741 , um pouco superior àquele resultante da análise do PAA.

A constatação de períodos curtos (15 min ou $30 \mathrm{~min}$ ) para aquisição ou transmissão de begomovírus em tomateiro reforçam a importância de $B$. tabaci biótipo B na rápida disseminação do vírus no campo. Resultados similares aos obtidos com o GO-ANPL foram relatados para begomovírus que infetam algodão, tomate e cucurbitáceas em outros países (Cohen et al., 1983; Metha et al., 1994b; Nateshan et al., 1996; Idris \& Brown, 1998). Os percentuais de infecção correspondentes aos tempos mínimos para aquisição ou transmissão dos begomovírus, porém, variam bastante com a espécie ou mesmo com o isolado viral envolvido. Segundo Duffus (1996), os begomovírus diferem entre si, em suas relações de aquisição e persistência na mosca branca, e podem diferir em outras características de interações com o inseto vetor.

O período de latência do GO-ANPL em $B$. tabaci biótipo B de $16 \mathrm{~h}$, aproxima-se ao de outros begomovírus como o TYLCV, isolado da Jordânia, que foi de 20 h (Mansour \& AlMusa, 1992) e do SCLV, que foi de $19 \mathrm{~h}$ (Coehn et al., 1983) com 15 a 20 insetos (B. tabaci biótipo A) por planta. Período de latência inferior ao GO-ANPL, porém, foi relatado para o ToLCV-Ban $4(6 \mathrm{~h})$ com cinco insetos/planta (Muniyappa et al., 2000).

Os dados obtidos com as variáveis estudadas na relação do GO-ANPL com a B. tabaci biótipo B, evidenciando a maior eficiência na transmissão do begomovírus com o aumento do PAA ou do PAI e um PL de 16 h, estão de acordo com a modalidade de transmissão do tipo circulativa (Costa, 1976; Rossell et al., 1999).

A detecção do GO-ANPL foi registrada em todos os ínstares do vetor desenvolvidos em planta infetada, tendo sido maior o percentual de detecção do vírus nos últimos estágios ninfais. Estes dados diferem daqueles obtidos por Polston et al. (1990) para o SLCV, nos quais o DNA viral foi detectado em apenas uma ninfa de $B$. tabaci biótipo A dentre as 196 testadas individualmente e em nenhuma das 335 ninfas testadas em grupos de cinco a dez pelos autores. Segundo Lastra (1993), ainda que as ninfas de mosca branca possam adquirir o vírus alimentando-se em planta infetada, o seu hábito séssil as impedem de ter algum papel na transmissão do vírus do ponto de vista epidemiológico. Contudo, contrariando o que afirma esse autor, a participação das ninfas na aquisição do GO-ANPL e a conseqüente passagem transestadial do vírus para o adulto, revela a importância das ninfas na epidemiologia da virose, uma vez que adultos emergindo de "pupas" desenvolvidas em plantas infetadas, mesmo sob baixa população, podem disseminar vírus em uma plantação. Elevados níveis de transmissão de vírus em tomateiro associados a baixo número de moscas brancas no campo foram anteriormente relatados (Lima et al., 2001).

O GO-ANPL não foi detectado em nenhuma das amostras constituídas de grupos de 20 ovos coletados após cinco a sete dias da oviposição realizada por fêmeas avirulíferas de B. tabaci biótipo B em planta infetada. Este resultado indica que não ocorre a passagem do vírus juntamente com a água veiculada para os ovos através de pedicelos ou hastes. Observação semelhante foi realizada por Ghanim et al. (1998) em ensaios realizados para o TYLCV. Segundo Weber, citado por Byrne \& Bellows (1991), a água presente na folha passa osmoticamente através de uma massa coloidal e entra no ovo de Trialeurodes vaporariorum Westwood através do pedicelo. 
Estudo da interação de um begomovírus isolado de tomateiro com...

autores citam ainda que Gameel, em 1974, relatou um processo similar ocorrendo com B. tabaci biótipo A e que outras pesquisas têm sugerido que aleirodídeos usam o pedicelo como forma de absorver a água.

Por meio da PCR foi possível detectar o GO-ANPL em adultos com PAA de 30 min a $24 \mathrm{~h}$ em planta infetada, observando-se um aumento no percentual de detecção com o aumento do tempo para a aquisição do vírus. A não detecção do vírus nos adultos com PAA de 15 min pode ter sido em razão do baixo número de amostras testadas, uma vez que com esse tempo de alimentação, a transmissão do vírus do inseto para mudas de tomateiro ocorreu em $6 \%$ dos casos. Resultados semelhantes a estes foram observados por Muniyappa et al. (2000) para o ToLCV, em que o DNA viral foi amplificado a partir de insetos com PAA de $30 \mathrm{~min}$, mas não daqueles com PAA de 15 min. Em ensaios com fêmeas individuais que tiveram um PAA contínuo de $24 \mathrm{~h}$ em tomateiro infetado com o GOANPL, o vírus foi detectado em $63 \%$ dos casos, indicando que é possível que ocorra variação na capacidade de aquisição de DNA viral entre fêmeas de mosca branca. Oscilações similares no percentual de detecção viral em indivíduos com diferentes PAAs foram relatadas anteriormente por Rossell et al. (1999) e Polston et al. (1990).

Na relação GO-ANPL e B. tabaci biótipo B, a passagem transestadial foi detectada em todos os adultos emergentes testados sugerindo que, nessa relação, a retenção do vírus após a última ecdise ocorre com elevada frequiência. Estes resultados diferem daqueles obtidos por Polston et al.(1990) para o SLCV, que não detectaram o begomovírus em 63 adultos de B. tabaci biótipo A testados, e para o CLCuV no mesmo vetor (Costa, 1976). Contudo, para alguns begomovírus de tomateiro, como o TYLCV, e de plantas daninhas a passagem transestadial em $B$. tabaci biótipo A foi também registrada (Costa, 1976). Na relação GO-ANPL com o vetor, observou-se ainda que o percentual de transmissão viral de $33 \%$ observado nos testes de transmissibilidade pelos adultos emergentes acima referidos, foi similar àquele obtido nos ensaios em que 0 PAA concedido às moscas brancas avirulíferas foi de $4 \mathrm{~h}$ em planta infetada (Tabela1).

As informações aqui obtidas indicam que a PCR pode ser empregada em estudos epidemiológicos para a detecção da presença de begomovírus na área de plantio de tomateiro, ou em suas proximidades, a partir de moscas brancas coletadas no campo, em tomateiro ou em outras espécies vegetais.

$\mathrm{O}$ isolado GO-ANPL, ainda que em percentual relativamente baixo, foi constatado em todas as fases de desenvolvimento da progênie oriunda de fêmeas virulíferas, diferindo dos resultados negativos de transmissão à progênie obtidos nas investigações com o Euphorbia mosaic virus (EuMV) (Harrison, 1985), com o Sinaloa tomato leaf curl virus (STLCV) (Idris \& Brown, 1998) e para o SLCV (Cohen et al., 1983). Neste último caso, os autores não detectaram o vírus em pelo menos 1.000 adultos de primeira geração oriundos de fêmeas virulíferas. Contudo, para o TYLCV, begomovírus de genoma monopartido, a transmissão transovariana foi registrada em percentuais bastante elevados (36-80\%) em ovos, ninfas e adultos da progênie (Ghanim et al., 1998).

A não constatação da transmissão do GO-ANPL para tomateiro pelos adultos de mosca branca provenientes da progênie de fêmeas virulíferas foi baseada na ausência de infecção viral em 23 plantas de tomateiro, nas quais esses adultos permaneceram por 48 horas. Em ensaios conduzidos com o TYLCV, Ghanim et al. (1998) constataram uma transmissão viral de $10 \%$ obtida a partir de 50 plantas submetidas aos adultos da progênie de primeira geração de fêmeas virulíferas. Os autores observaram, no entanto, que em pelo menos um dos ensaios conduzidos com grupos de 20 plantas, nenhum tomateiro foi infetado pelo TYLCV. Diante disto, é possível imaginar que os resultados obtidos para o GO-ANPL diferissem de zero, caso o ensaio de transmissão do vírus pelos adultos da progênie tivesse sido realizado com um maior número de plantas.

A diversidade genética das espécies de begomovírus de tomateiro constatada no Brasil tem sido atribuída à presença de plantas daninhas e da mosca branca vetora no campo (Ambrozevicius et al., 2002; Ribeiro et al., 2003). Apesar dessa diversidade, o ToRMV, espécie com a qual o isolado GO-ANPL apresenta um relacionamento genético próximo, e o Tomato chlorotic mottle virus (ToCMV) ambas recentemente descritas, têm sido as mais frequientemente encontradas na região de Minas Gerais (Zerbini et al., 1996; Ambrozevicius et al., 2002). De modo similar ao que se observa com os tospovírus no campo, a predominância de outros begomovírus nas demais áreas produtoras de tomate no Brasil poderá estar, provavelmente, associada às espécies de plantas daninhas (fontes de vírus) típicas ou predominantes em cada região, somada à variação na eficiência de transmissão desses begomovírus pela mosca branca. No caso dos tospovírus, o Tomato spotted wilt virus (TSWV) foi a principal espécie detectada no Distrito Federal e Paraná, o Tomato chlorotic spot virus (TCSV) a predominante em São Paulo e a Groundnut ringspot virus (GRSV) a mais disseminada em Pernambuco, uma distribuição que, segundo Nagata et al. (1995), pode ter sido resultante de uma transmissão preferencial e diferencial dos tospovírus pelo tripes vetor.

Os resultados obtidos neste trabalho indicam que a interação begomovírus-vetor é estabelecida desde a fase inicial do desenvolvimento do inseto e podem ser considerados relevantes para os estudos epidemiológicos dos begomovírus de tomateiro associados ao biótipo B de B. tabaci no país.

\section{REFERÊNCIAS BIBLIOGRÁFICAS}

AMBROZEVICIUS, L.P., CALEGÁRIO, R.F., FONTES, E.P.B., CARVALHO, M.G. \& ZERBINI, F.M. Diversidade genética de begomovírus infetando o tomateiro e plantas daninhas no Sudeste do Brasil. Fitopatologia Brasileira 27:372-377. 2002.

BEZERRA, I.C., RIBEIRO, S.G., ÁVILA, A.C. \& GIORDANO, L.B. Survey of geminivirus in tomato producing areas in Federal District. Resumos, $8^{\circ}$ Encontro Nacional de Virologia, São Lourenço, MG. 1996. p.289.

BROWN, J.K., FROHLICH, D.R. \& ROSSEL, R.C. The 
C.D.G. Santos et al.

sweetpotato or silverleaf whiteflies:biotypes of Bemisia tabaci or a species complex? Annual Review of Entomology 40:511-534. 1995.

BROWN, J.K. The biology and molecular epidemiology of the Geminiviridae subgroup III. In:Stacey, G.E \& Keen, N.T. (Eds). Plant-Microbe Interactions. New York. ITP. 1997. pp.125-195.

BYRNE, D.N. \& BELLOWS JUNIOR, T.S. Whitefly biology. Annual Review of Entomology 36:431-457. 1991.

COHEN, S., DUFFUS, J.E. \& LIU, H. Acquisition, interference, and retention of cucurbit leaf curl viruses in whiteflies. Phytopathology 79:109-113. 1989.

COHEN, S., DUFFUS, J.E., LARSEN, R.C., LIU, H. \& FLOCK, R.A. Purification, serology and vector relationships of squash leaf curl virus, a whitefly-transmitted geminivirus. Phytopathology 73:1669-1673. 1983.

COSTA, A.S. Whitefly-transmited plant diseases. Annual Review of Phytopathology 14:429-449. 1976.

DELLAPORTA, S. L., WOOD, J. \& HICKS, J.B. A plant DNA minipreparation: version II. Plant Molecular Biology Reporter 1:1921. 1983.

DUFFUS, J. E. Whitefly-borne viruses. In: Gerling, D. \& Mayer, RT. (Eds). Bemisia 1995: Taxonomy, Biology, Damage, Control and Management. Andover: Intercept 1996. pp.255-263.

FRANÇA, F.H., VILLAS-BÔAS, G.L. \& CASTELO BRANCO, M. Ocorrência de B. argentifolii Bellows \& Perring (Homoptera: Aleyrodidae) no Distrito Federal. Anais da Sociedade Entomológica do Brasil 25:369-372. 1996.

FARIA, J.C., BEZERRA, I.C., ZERBINI, F.M., RIBEIRO, S.G.\& LIMA, M..F. Situação atual das geminiviroses no Brasil. Fitopatologia Brasileira 25:125-137. 2000.

GHANIM, M., MORIN, S., ZEIDAN, M \& CZOSNEK, H. Evidence for transovarial transmission of Tomato yellow leaf curl virus by its vector, the whitefly Bemisia tabaci. Virology 240:295303. 1998.

HARRISON, B.D. Advances in geminivirus research. Annual Review of Phytopathology 23:55-82. 1985.

HOROWITZ, A.R., PODOLER, H. \& GERLING, D. Life table analysis of the tobacco whitefly Bemisia tabaci (Gennadius) in cotton fields in Israel. Acta ecologica/Oecologica Applicata 5:221233. 1984.

IDRIS, A.M. \& BROWN, J.K. Sinaloa tomato leaf curl geminivirus:biological and molecular evidence for a new subgroup III virus. Phytopathology 88:648-657. 1998.

LASTRA, R. Los geminivirus:un grupo de fitovirus com caracteristicas especiales. Memorias Taller Centroamericano y del Caribe sobre Moscas Blancas. Turrialba, 1993. pp.16-19.

LIMA, M.F., BEZERRA, I.C., RIBEIRO, S.G. \& AVILA, A.C. Distribuição de geminivírus nas culturas do tomate e pimentão em doze municípios do Submédio do Vale do São Francisco. Fitopatologia Brasileira 26:81-85. 2001.

MANSOUR, A. \& AL-MUSA, A. Tomato yellow leaf curl virus: host range and virus-vector relationships. Plant Pathology 41:122125. 1992.

METHA, P., WYMAN, J.A., NAKHLA, M.K. \& MAXWELL, D.P. Polymerase chain reaction detection of viruliferous Bemisia tabaci (Homoptera: Aleyrodidae) with two tomato-infecting geminiviruses. Journal of Economic Entomology 87:1285-1290. 1994 a.
METHA, P., WYMAN, J.A., NAKHLA, M. K. \& MAXWELL, D.P. Transmission of tomato yellow leaf curl geminivirus by Bemisia tabaci (Homoptera: Aleyrodidae). Journal of Economic Entomology 87:1291-1297. 1994b.

MORIN, S., GHANIM, M; ZEIDAN, M; CZOSNEK, H; VERBEEK, M. \& VAN DEN HEUVELT, F.J.M. A Groel homologue from endosymbiotic bacteria of the whitefly Bemisia tabaci is implicated in the circulative transmission of tomato yellow leaf curl. Virology 256:75-84. 1999.

MUNIYAPPA, V. VENKATESH, H. M., RAMAPPA, H. K., KULKARNI, R. S., ZEIDAN, M. TARBA, C.Y., GHANIM, M. \& CZOSNEK, H. Tomato leaf curl virus from Bangalore (ToLCVBand4): sequence comparison with Indian isolates, detection in plants and insects, and vector relationships. Archives of Virology 145:1583-1598. 2000.

NAGATA, T., ÁVILA, A.C., TAVARES, P.C.T.M., BARBOSA, C.J., JULIATTI, F.C. \& KITAJIMA, E.W. Occurrence of different tospovirus in six states of Brazil. Fitopatologia Brasileira 20:90-95. 1995.

NATESHAN, H. M., MUNIYAPPA, V., SWANSON, M..M. \& HARRISON, B.D. Host range, vector and serological relationships of cotton leaf curl virus from southern India. Annual Applied Biology 128:233-244. 1996.

PICÓ, B., DIEZ, M..J. \& NUEZ, F. Viral diseases causing the greatest economic losses to the tomato crop. II Tomato yellow leaf curl virusa review. Scientia Horticulturae 67:151-196. 1996.

POLSTON, J.E., AL-MUSA, A., PERRING, T.M. \& DODDS, J.A. Association of the nucleic acid of Squash leaf curl geminivirus with the whitefly Bemisia tabaci. Phytopathology 80:850-856. 1990.

RIBEIRO, S.G., AMBROZEVÍCIUS, L.P., ÁvilA, A.C., BEZERRA, I.C., CALEGARIO, R.F., FERNANDES, J.J., LIMA, M.F., MELLO, R.N., ROCHA, H.C. \& ZERBINI, F.M. Distribution and genetic diversity of tomato-infecting begomovirus in Brazil. Archives of Virology 148: 281-295. 2003.

ROM, M., ANTIGNUS, Y., GIDONI, D., PILOWSKY, M. \& COHEN, S. Accumulation of Tomato yellow leaf curl virus DNA in tolerant and susceptible tomato lines. Plant Disease 77:253257. 1993.

ROSSELL, R.C. TORRES-JEREZ, I. \& BROWN, J.K. Tracing the geminivirus-whitefly transmission pathway by polimerase chain reaction in whitefly extracts, saliva, hemolymph, and honeydew. Phytopathology 89:239-246. 1999.

RUBINSTEIN, G. \& CZOSNEK, H. Long-term association of Tomato yellow leaf curl virus with its whitefly vector Bemisia tabaci: effect on the insect transmission capacity, longevity and fecundity. Journal of General Virology 78: 2683-2689. 1997.

SANTOS, C.D.G., ÁVILA, A.C. \& RESENDE, R.O. Determination of virus/vector interaction of a new begomovirus isolated from tomato in the State of Goiás, Brazil. Resumos, $13^{\circ}$ Encontro Nacional de Virologia, Águas de Lindóia, SP.2002a. pp.151-152.

SANTOS, C.D.G., BEZERRA, I.C., ÁVILA, A.C. \& RESENDE, R.O. Occurrence of geminivirus in tomato crops in the state of Goiás. Resumos, $10^{\circ}$ Encontro Nacional de Virologia, São Lourenço, MG. 1998. p.144.

SANTOS, C.D.G., INOUE NAGATA, A., ÁVILA, A.C. \& RESENDE, R.O . Molecular characterization of a new begomovirus isolated from tomato in the State of Goias, Brazil.. Resumos, $13^{\circ}$ 
Estudo da interação de um begomovírus isolado de tomateiro com...

Encontro Nacional de Virologia, Águas de Lindóia, SP. 2002b. p.153.

VILLAS-BÔAS, G.L., FRANÇA, F.H., NEWTON, M. \& ELIAS, M.F. Predominância do biótipo B de mosca branca (Bemisia argentifolii) em diversos hospedeiros e regiões do Brasil. Anais, $8^{\circ}$ Encontro Latino-americano e do Caribe Sobre Moscas Brancas e
Geminivirus, Recife, 1999. p.150.

ZERBINI, F.M., ZAMBOLIM, E.M., CARRIJO, I.V. \& GILBERTSON, R.L. A new bipartite geminivirus infecting tomatoes in Minas Gerais, Brazil. Phytopathology 86:S1. 1996 (Abstract). 